\title{
Adrián Ascolani y Miguel Catalá. Humberto Volando. El líder agrario, Argentina 1964-1996. Buenos Aires: CICCUS, 2017, 336 páginas.
}

\author{
Gabriel Fernando Carini \\ Universidad Nacional de Río Cuarto \\ Universidad Nacional de Córdoba \\ Consejo Nacional de Investigaciones \\ Científicas y Técnicas \\ gcarini@hum.unrc.edu.ar
}

(Argentina)

Recibido: 07-02-2020

Aceptado: $11-05-2020$

Publicado: 05-06-2020

El libro de Adrián Ascolani y Miguel Catalá recupera, a través de las intervenciones públicas reproducidas en la prensa agraria, la trayectoria gremial de unos de los principales dirigentes de la segunda mitad del siglo XX: Humberto Volando, productor ganadero de la provincia de Córdoba, que tuvo bajo su dirección los destinos de la Federación Agraria Argentina (en adelante, FAA). Podemos afirmar que este aporte se inscribe en una dilatada preocupa- ción de miembros de dicha entidad por relatar los aspectos más sobresalientes de las gestiones de sus líderes. ${ }^{1}$ Muchas de estas visiones son institucionalizantes, puesto que contribuyen a fijar la memoria de la entidad y/o exaltar la figura de sus líderes ubicándolos en una suerte de "panteón". Así, Humberto Volando ingresa a ese selecto conjunto de líderes carismáticos -en términos weberianos- que condujeron los destinos de la institución por extensos períodos; sin dudas, una de las características fundantes de la entidad.

El libro se estructura en seis capítulos que abarcan los más de treinta años que Humberto Volando ocupó altas posiciones institucionalizadas de la entidad federada. Así, los autores proponen un recorte que va desde la participación de Volando como representante de la Corporación Argentina de Productores de Carne (CAP) y vicepresidente de la FAA en 1964 hasta la culminación de su mandato

1. Véase a modo de ejemplo para la FAA los trabajos de Grela (1958); García Serrano (1967); Diecidue (1969). 
en 1996 para volcarse a la política partidaria, esta vez, como diputado nacional en representación del Frente País Solidario (FREPASO). Ese marco temporal se organiza con un criterio político-institucional donde se aborda la actuación de Volando frente a las diversas políticas económicas implementadas por los gobiernos de turno.

Estos recortes permiten acceder a diferentes dimensiones que constituyen vías de ingreso a los contextos múltiples en los que participan los actores. Consideramos que una de las más destacadas es la que posibilita -a partir de la figura de Volando- explorar la dinámica institucional de la secular entidad agraria. En ese sentido, un punto destacado es la recuperación de fuentes de la FAA que sintetizan no solo las discusiones internas del devenir de la entidad, sino también las percepciones y representaciones construidas por la dirigencia rural en torno al Estado y los efectos de las políticas económicas. Particularmente relevantes en la investigación son las opiniones vertidas en sus congresos anuales. Estos momentos son de los más significativos en la vida de las instituciones y sus 'mensajes' no solo sirven para dar cuenta de lo actuado, reforzar el vínculo con los asociados, sino también para canalizar demandas hacia otros actores, en especial, al Estado. Metodológicamente, son empleados por los autores para la reconstrucción minuciosa de las opiniones -organizadas cronológicamente- vertidas por el biografiado ante diversas medidas económicas implementadas por los gobiernos en el período considerado. Resultaría significativo profundizar las implicancias que tuvo la utilización del periódico La Tierra, creado casi al unísono con la institución, los cambios y continuidades en su línea editorial, la incorporación de demandas al programa reivindicativo históricamente soste190 nidos por la dirigencia federada que permitan distinguir la 'voz' de Volando respecto a otros editores y, de esa forma, ponderar el rol fundamental de La Tierra en la construcción de su liderazgo. ${ }^{2}$ Algunos elementos de esta cuestión se encuentran en el libro y seguramente brindarán elementos para futuras indagaciones, especialmente, para aquellos que quieran explorar los procesos de identificación de los productores.

Otra dimensión que se hace presente en el texto se refiere al programa gremial que impulsó Volando, es decir, el conjunto de demandas que orientaron la mediación política frente al Estado y que delinearon las estrategias en el espacio público, implicando, por ejemplo, las acciones de protesta o la conformación de frentes sectoriales o intersectoriales. En esa construcción, uno de los aspectos más relevantes es cómo se construye discursivamente la idea de la necesidad de una "reforma agraria integral". El recorrido propuesto permite inferir que esta noción implicaba una serie de acciones que el Estado debía implementar para mejorar la situación de los "auténticos productores". Estas acciones, básicamente, requerían de una reforma impositiva que sobre el principio de la progresividad grabara a las tierras improductivas favoreciendo la erradicación de los latifundios y, consecuentemente, permitiera el acceso a la propiedad de la tierra a los productores directos. Asimismo, se complementaba con el fomento del cooperativismo y de otras formas comunitarias de trabajo rural. Indudablemente, como queda evidenciado en el libro, esta forma de concebir las necesidades de su base social posibilitó tanto la construcción de consensos y alianzas con otros sectores

2. Un estudio sobre las textualidades construidas por el periódico La Tierra y la noción de reforma agraria puede encontrarse en Poggi (2013). 
productivos y políticos como la confrontación al interior de la red de representación de intereses agrarios. Un ejemplo claro en el período analizado por los autores fue la recepción que tuvo entre 1973 y 1974, por parte de Volando, el proyecto del entonces Secretario de Agricultura, Horacio Giberti. Ahora bien, no necesariamente el recorrido propuesto permite observar cómo ingresan estos tópicos al conjunto de demandas sostenidas en períodos previos por la dirigencia federada. Es decir, cuáles fueron efectivamente los lineamientos que el discurso de Volando logró introducir en el repertorio históricamente sostenido por la FAA, cuál fue la ruptura que produjo su pensamiento y que permitió que pasara a ser incluido entre los máximos "conductores" de la entidad y que proyectara su influencia sobre diversas generaciones de dirigentes agrarios. Los autores proporcionan claves que vuelven inteligible -en parte- esa cuestión, como, por ejemplo, la adhesión inicial de Volando al Partido Demócrata, la asidua lectura de la revista Criterio o la mención al pensamiento cristiano, más concretamente, a la doctrina social de la iglesia condensado en diversas encíclicas papales. Estas sociabilidades políticas podrían explicar mucho sobre las percepciones del biografiado, la familia y las juventudes rurales, el trabajo y la concepción de la tierra, el Estado y los regímenes políticos y cómo se vuelcan tanto a su discursividad como a las acciones políticas concretas por él emprendidas. De esta manera, se podría contrastar las resignificaciones de las demandas históricamente sostenidas por la dirigencia de FAA, las rupturas en el repertorio reivindicativo $y$, si se quiere, la vigencia de la discursividad de Volando en distintas coyunturas.

También emerge del análisis de la trayectoria propuesta por los autores aspectos escasamen- te explorados por la historiografía como la acción política ejercida por la dirigencia agraria en momentos que no son de conflicto explícito sino que, por el contrario, son campos de negociación que habilitan el despliegue de diversas estrategias. Nos referimos puntualmente a aquellas instancias que posibilitan el ejercicio de la influencia en las arenas decisionales del Estado y, por ende, en el diseño de políticas sectoriales. Esto abre una dimensión interesante para ser profundizada, dado que generalmente los investigadores le han otorgado visibilidad a instancias de alta performatividad política como las protestas sociales. En conexión con las modalidades que asume la mediación política y, puntualmente, cómo se asienta sobre ciertos discursos y representaciones. Por ejemplo, el de la -en términos de la dirigencia rural- "vocación democrática", o sea, la valoración y compromiso que asumen en la defensa del régimen político democrático y la capacidad que le asignan para resolver las problemáticas sectoriales. Esta cuestión remite a una forma de comprensión de las prácticas de la dirigencia de las entidades agropecuarias que asocia mecánicamente a entidades de pequeños productores con un pensamiento de tipo progresista y, en contrapartida, entidades de medianos y grandes productores con formas más conservadoras. ${ }^{3}$ Lo que pone de manifiesto la propuesta de los autores es la continuidad que existe en la capacidad de mediación política, de Volando en particular y de la FAA en general, más allá de las discontinuidades institucionales. Esto se evidenció, entre otros momentos, durante el gobierno de facto de Agustín Lanusse (1971-1973) mientras An-

3. Sanz Cerbino (2014) introduce algunos comentarios sugerentes sobre este asunto para el análisis de la coyuntura 1966-1973. No obstante, consideramos que sus implicancias trascienden esos límites temporales y se convierte en una suerte de a priori analítico. 
tonio Di Rocco, presidente de la FAA, fue Ministro de Agricultura de la Nación o bien la recepción alentadora -como la de amplios sectores sociales- que hicieron las dirigencias rurales del gobierno de facto del autodenominado 'Proceso de Reorganización Nacional' (1986-1983). La posibilidad de accesos más fluidos a los espacios decisionales del Estado en momentos de proscripción de otros mecanismos de mediación política convierte a estos actores en interlocutores privilegiados con los gobiernos. Es decir, más allá de la efectiva convicción con las ideas de esos gobiernos está la defensa de los intereses sectoriales. No obstante, dicha dimensión requeriría de más trabajos para contradecir muchas percepciones que sobre estos actores o que, incluso las mismas bases sociales, construyen sobre los regímenes políticos.

A modo de cierre, consideramos que el libro es una significativa contribución que esperamos allane el camino para experiencias similares. El estudio de las trayectorias de los dirigentes rurales, en particular de aquellos que también ocuparon posiciones en los partidos políticos o en la burocracia estatal, resulta un terreno fértil para problematizar las visiones excluyentes que generalmente abundan sobre la relación entre gobiernos, partidos políticos y corporaciones agrarias. 


\section{Referencias Bibliográficas}

Diecidue, A. (1969). Netri: Lider y mártir de una gran causa. Rosario: Federación Agraria Argentina.

García Serrano, T. (1967). Esteban Piacenza. Apuntes biográficos. Buenos Aires: Ediciones Ruiz.

Grela, P. (1958). El Grito de Alcorta. Historia de la rebelión campesina de 1912. Rosario: Nuestra Tierra.

Poggi, M (2011). Problemática Agraria y prensa escrita en la Argentina de los años '70. Representaciones y debates sobre la propiedad de la tierra (Tesis doctoral inédita). Universidad Nacional de Quilmes, Argentina.

Sanz Cerbino, G. (2014). Antecedentes históricos de la unidad de las corporaciones agropecuarias pampeanas. La formación de la Comisión de Enlace y la disputa por la renta (1966-1973). Mundo Agrario, 15(29). Recuperado de https://www.mundoagrario.unlp.edu.ar/article/view/MAv15n29a09 